\title{
Teeth at the Wellcome Collection
}

The Wellcome Collection's summer exhibition on 'Teeth' is the first exhibition to chart the history of the dental profession that has shaped the way society lives, with or without teeth. The exhibition features over 150 objects that have been assembled from Henry Wellcome, the Northern European collections and the British Dental Association.

From barber-surgeons to professional dentists, the origins of dentistry are explored. The exhibition features the first scientific treatise on teeth. Le Chirugien-Dentiste (the SurgeonDentist), 1728, by Pierre Fauchard, which is displayed with examples of early techniques and tools. Dental care for the wealthy is shown through specimens, such as dentures belonging to King William IV and Napoleon's toothbrush. The blacksmiths who performed extractions for the less privileged are depicted in paintings, with caricatures by Thomas Rowlandson contrasting the suffering of the poor.

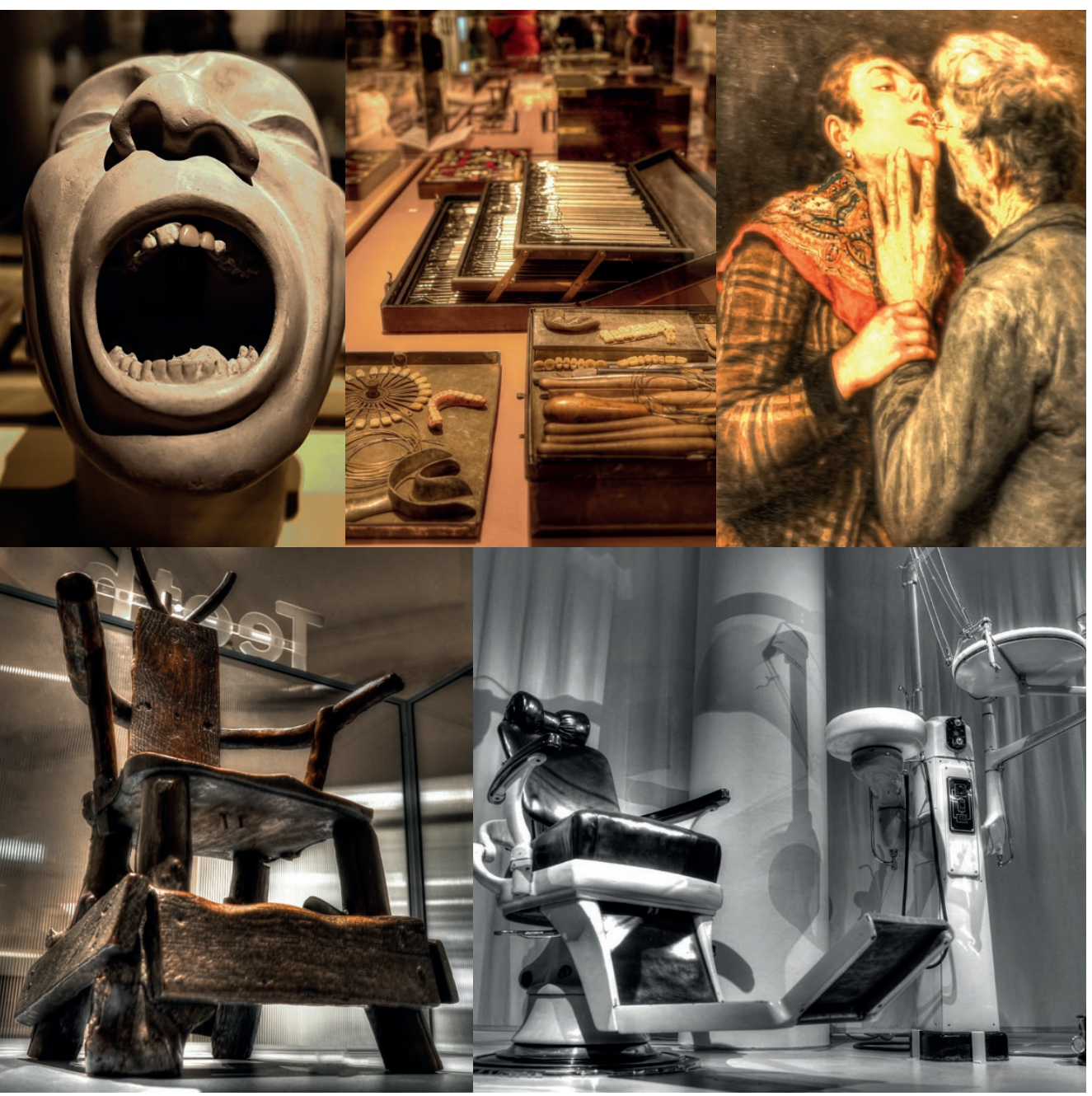

The progression in the technology behind dental drills, radiographs and anaesthetic is gradually revealed. The exhibition also displays the changing availability of consumer products such as toothpastes and brushes. The evolving ideas on the importance of oral hygiene are presented through poster campaigns, films and animations.

Whilst walking through the exhibition, it is made clear that the development of modern dentistry has come to represent a great deal more than physical health. Teeth are shown to be intrinsically linked to identity, both individual and cultural. The exhibition considers the language we use around teeth, such as gnashing them, gritting them or lying through them, and examines the tensions surrounding dental care, whether for health, comfort or confidence. Admission to this London exhibition is free and it runs until the 16 September 2018, so if ๑ँ you haven't popped in already, it’s definitely worth a visit!

By Reena Wadia 